\title{
FATIGUE ANALYSIS OF THE KNEE JOINT
}

\author{
Dr.C.Shashishekar ${ }^{1}$, S.J.Sanjay ${ }^{2,}$ Uday.P.Talawar ${ }^{3}$ \\ ${ }^{1}$ Associate Professor, Department of Mechanical Engineering Siddaganga Institute of Technology, \\ Tumakuru, Karnataka
}

${ }^{2}$ Assistant Professor, Mechanical Engineering, S.J.Sanjay, Basaveshwar Engineering college, Bagalkot, Karnataka

${ }^{3}$ PG - Mechanical Engineering, Basaveshwar Engineering College, Bagalkot, Karnataka

\begin{abstract}
The knee joint is quite possibly the main piece of the human body. So Demonstrating and reproducing it for various pressure conditions can assist us with understanding its mechanical conduct. Knee joint comprises of various segments, for example femur and tibia which makes it complex design, going through various basic burdens in human body performing movements and proactive tasks. Here we made a knee joint model with legitimate measurements utilizing strong edge programming. The current investigation centers on the weakness examination of the knee joint. The investigation of the typical knee under cyclic stacking assists us with find out about the existence of the get together. What's more, this weariness investigation is completed by utilizing ANSYS 18.1 workbench programming. Then, at that point the exhaustion results are seen with different boundaries. So in the wake of applying the specific limit conditions we will complete the weakness examination with various burdens. Weakness investigation can assist us with find out about the reasons for various knee joint problems. Metal amalgams have been the materials of decision since the beginning of muscular. So here the distinctive bio materials which are utilized here are Titanium amalgam (Ti-6Al-4V), Tempered steel, and Co-Cr-Mo. these are the three materials which are utilized for this specific activity. After that we remove the weariness results for the distinctive bio materials then we begins make the correlation for various bio materials with the assistance of results and graphical view.
\end{abstract}

Keywords — Knee joint, tibia, femur, fatigue, safety factor.

\section{INTRODUCTION}

The human knee joint is essential part of the body and it will be the continuous engaged part of the human body. So that this engage makes it very prone to degradation. And one more thing is that. Here we made a normal knee joint model with proper dimensions and then we assembled the femur and tibia by using proper software. After certain operation we identify the fatigue levels.

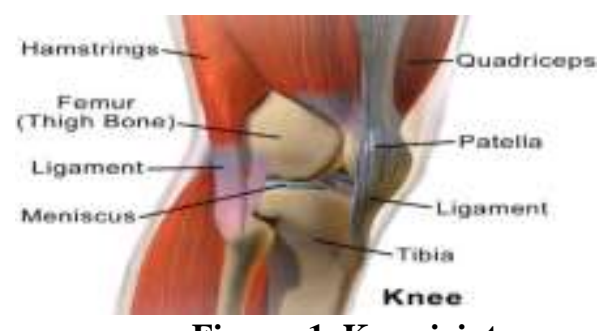

Figure .1. Knee joint

Also, the focuses which are having lesser factor of well being and the edge of security have been recognized alongside the weariness life of the framework with the assistance of recreations. What's more, something more we came to realize that a less number of explores have been done on the knee joint to comprehend its component, so I chose to step up to the plate. And furthermore tendons assume a significant part in the system of human knee joint. Very much like ligaments and ligaments. Also, something more is that besides, over twenty percent of the joint suffering pool, the most well-known bone problems, examined displayed torn tendons. So we came to realize that tendon do to be sure assume a part in anticipation of Ligament harm by holding the entire gathering firm [1]

By the assistance of Processed Tomography picture of a decent steady tolerant, they have fostered a three Dimensional segment from that they examined with the assistance of specific programming. By utilizing certain mechanical properties of specific materials we caused diverse activity to analyze the pressure to a specific area of a steady knee joint and furthermore wellbeing elements, and life of the model and afterward certain powers were given so that of genuine knee. Also, the powers differing range is $500-5000 \mathrm{~N}$ were applied and that specific mode was concentrated 


\section{International Advanced Research Journal in Science, Engineering and Technology}

Vol. 8, Issue 9, September 2021

DOI: 10.17148/IARJSET.2021.8927

under these powers so the framework results are positive and will be empowering when contrasted with different information accessible .so our significant focal point is concentrated under these heaps. [1]

\subsection{Basic concept of the fatigue}

- Fatigue is the commencement and proliferation of break in a substance because of cyclic stacking once exhaustion break has started, it grows a limited quantity with each stacking cycle, ordinarily delivering striations on certain pieces of the crack surfaces, The break will keep on developing until it arrives at a basic size, which happens when the pressure power factor of the break surpasses the crack sturdiness of the substance, creating fast engendering and commonly complete crack of the structure.[9]

- $\quad$ Fatigue failure is the development and engendering of break because of monotonous or cyclic stacking. Most exhaustion disappointment is brought about by cyclic loads essentially beneath the heaps that would bring about yielding of the substance. The disappointment occur because of the cyclic idea of the heap which causes minute (defects) to form into naturally visible crack(initiation stage) [10]

- $\quad$ Fatigue life is a mechanical and scientific ward that associate with to how long an object or substance will last before completely failing because of concentrated stress.[11]

- $\quad$ Fatigue safety factor it shows factor of wellbeing as for weakness disappointment. It goes from 1 to 1.5 if weakness wellbeing factor is short of what one substance will fall flat before plan life reached.[11]

- Fatigue damage is the proportion of plan life/accessible life. On the off chance that this worth is more prominent than 1, part will fall flat before plan life reached.[11]

- $\quad$ Fatigue sensitivity it shows variation in failure life fatigue damage and fatigue safety factor when current loading reduced or increased. [11].

\section{II._METHODOLOGY}

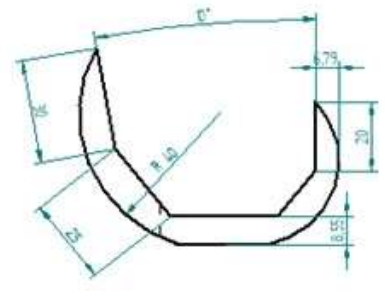

Fig.03 Two dimensional diagram of Femur

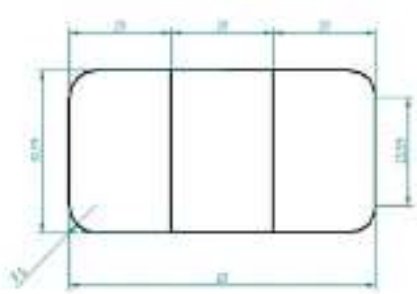

Fig.04 Two dimensional diagram of Tibia

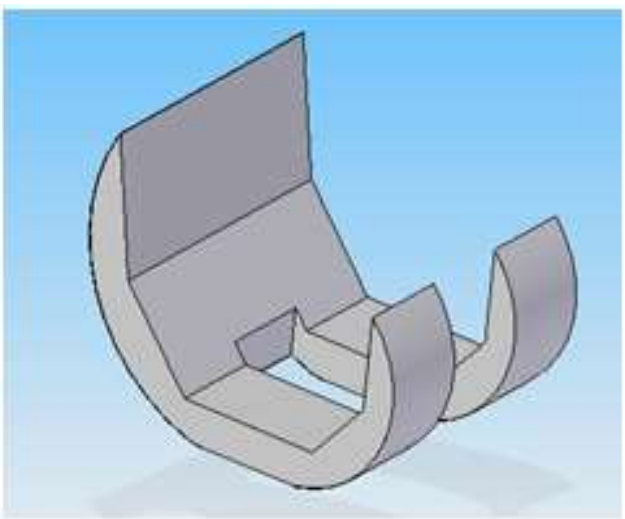

Figure 05: 3D View of femur

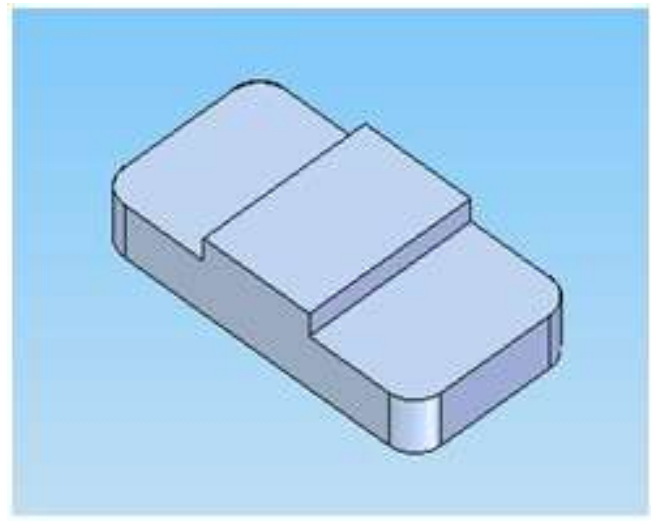

Figure 06: 3D View of tibia 
DOI: 10.17148/IARJSET.2021.8927

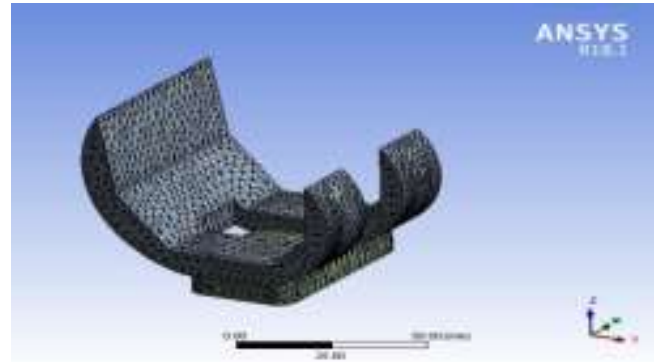

Fig 07: Assembly view

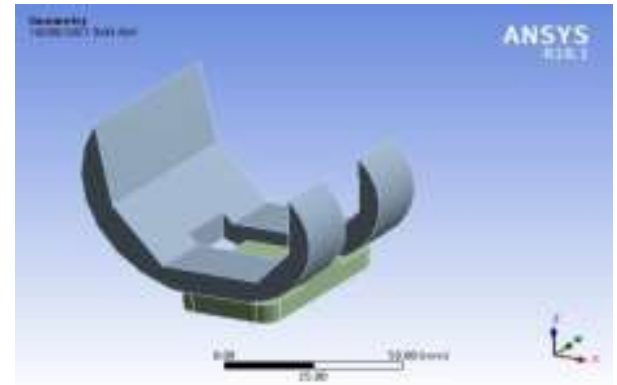

Fig 08: Meshed model

\subsection{Material used for component}

Most frequently bio-materials are utilized to obsession of different joint like hip, knee shoulder, lower leg or turn and bones in the body. What's more, here the biomaterial incorporates metal, artistic, Polymers and composites. Particularly titanium compound, cobalt-chromium combinations, and tempered steel. What's more, if there should arise an occurrence of polymer UHMWPE (ultra high atomic weight polyethylene) is regularly utilized biomaterial. As of late ceramics exhibited incredible guarantee for supplanting metals in complete knee supplanting with boss advantages of earthenware is their predominant wear properties

In this investigation titanium combination, cobalt-chromium composites, tempered steel and ultra high atomic weight polyethylene have been completed for weakness examination. Furthermore, here materials utilized for assembling the femoral segment are Ti-6Al-4V composite, Co-Cr-Mo amalgam and Treated steel. Furthermore, for Tibia ultra high sub-atomic weight polyethylene in every one of the cases.

\section{RESULTS AND DISCUSSION}

Here in this case Fatigue analysis was observed for knee joint model in ANSYS software. And the load range is from $500 \mathrm{~N}$ to $5000 \mathrm{~N}$ for various bio-materials.and here in this case the model can be viewed from various forms and judged by different parameters. Basically analysis was done for different materials and they are titanium compound, tempered steel., cobalt-chromium combinations for femur and for Tibia Polyethylene is used for all cases. For analysis purpose major parameter are fatigue life, Safety factor, Equivalent alternating stress, and Fatigue sensitivity.

$$
\text { FATIGUE RESULTS FOR Ti-6Al-4V }
$$

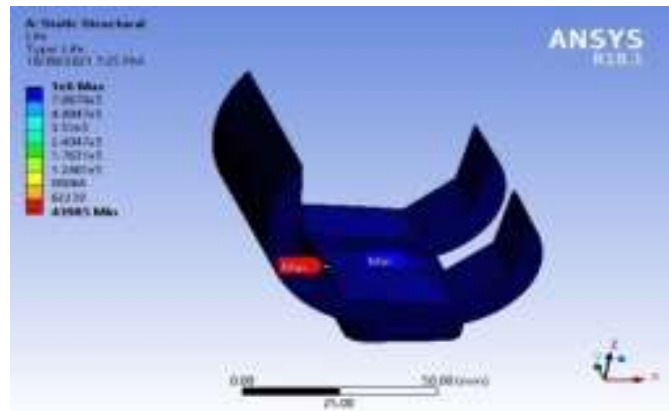

Figure 09: Fatigue life at 5000N

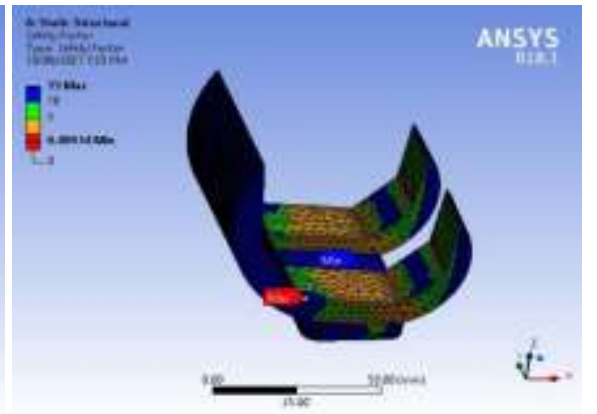

Figure 10: Fatigue safety factor for $5000 \mathrm{~N}$ 
International Advanced Research Journal in Science, Engineering and Technology

Vol. 8, Issue 9, September 2021

DOI: 10.17148/IARJSET.2021.8927

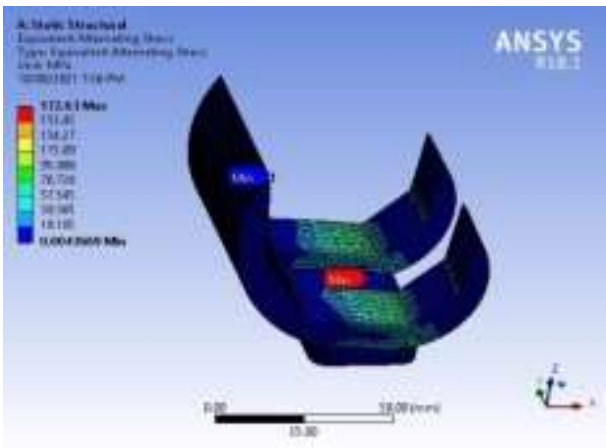

Figure 11: Equivalent alternating stress for $5000 \mathrm{~N}$

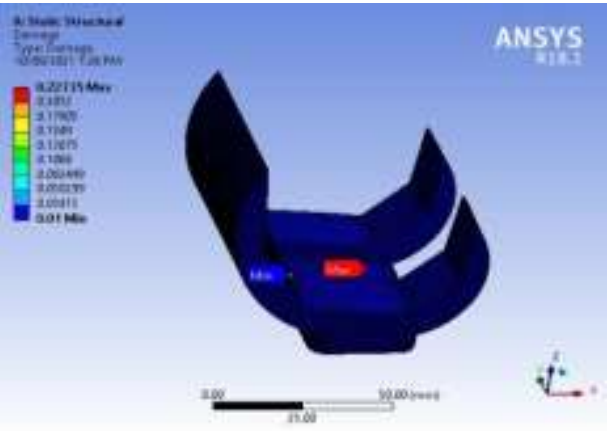

Figure.12: Fatigue damage for $5000 \mathrm{~N}$

(2) FATIGUE RESULTS FOR STAINLESS STEEL

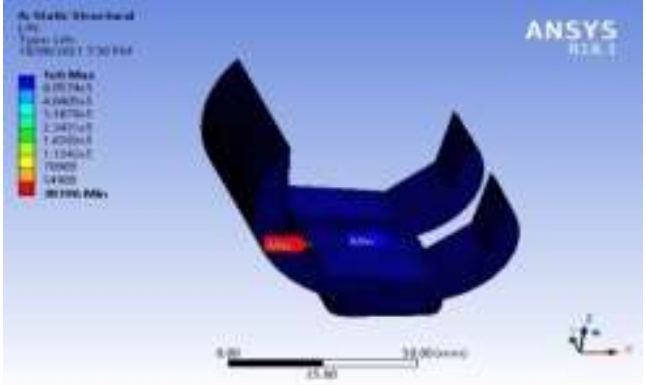

Figure.13: Fatigue life for $5000 \mathrm{~N}$

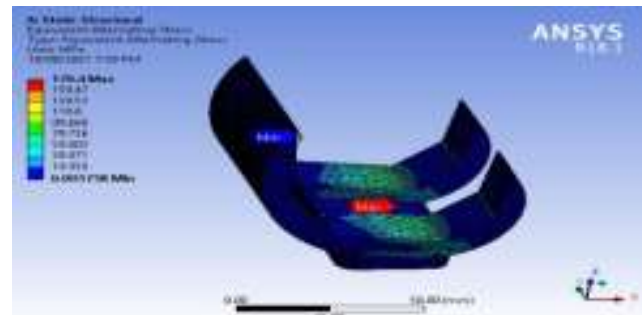

Figure.15: Equivalent alternating stress at $5000 \mathrm{~N}$

(2) FATIGUE RESULTS FOR Co-Cr-Mo ALLOY

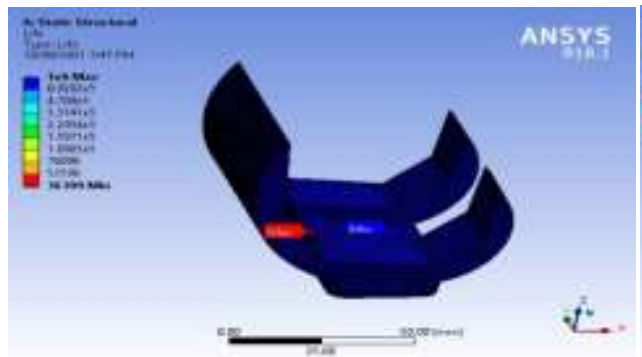

Figure 17: Fatigue life at 5000N

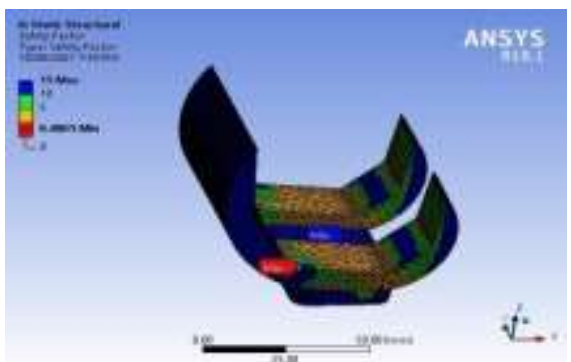

Figure. 14: Factor of safety at $5000 \mathrm{~N}$

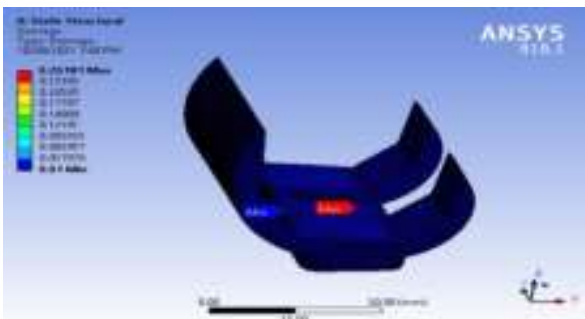

Figure. 16: Fatigue damage at 5000N

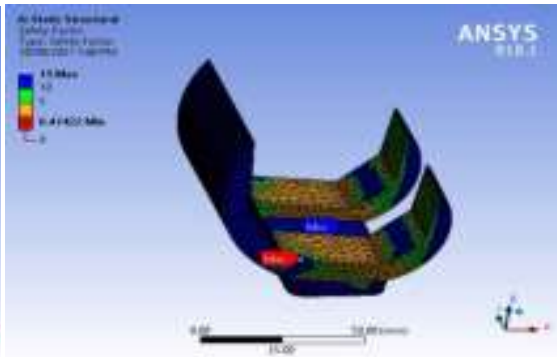

Figure 18: Fatigue safety factor at $5000 \mathrm{~N}$ 
Vol. 8, Issue 9, September 2021

DOI: 10.17148/IARJSET.2021.8927

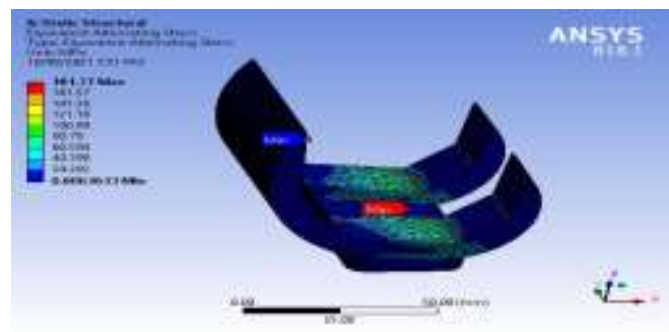

Figure 19: Equivalent alternating stress at $5000 \mathrm{~N}$

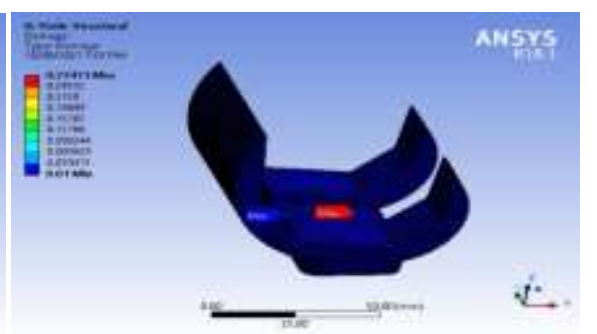

Figure 20: Fatigue damage at 5000N

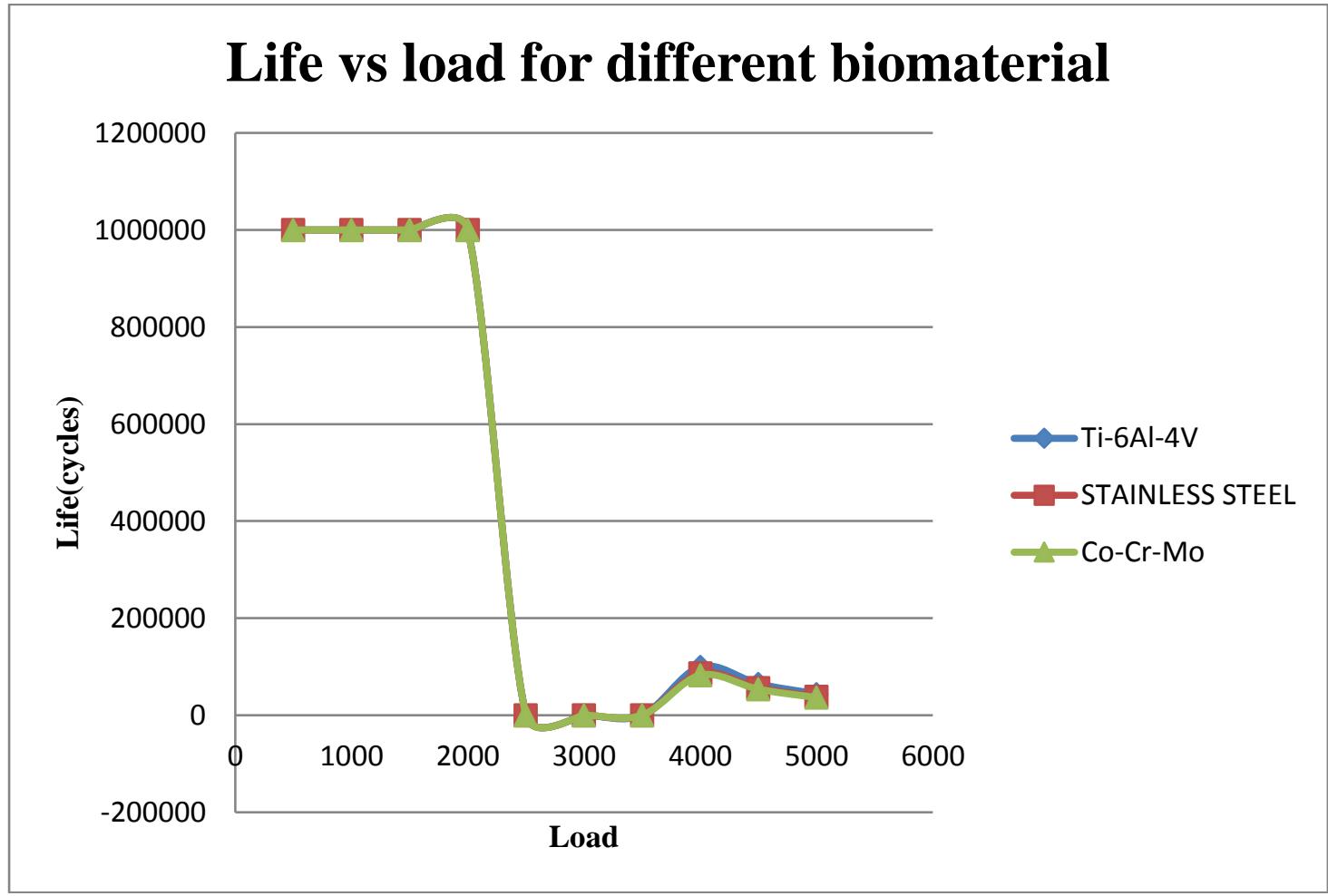

1. Graphical representation of life for different bio-material

Above figure shows the schematic representation of the life for different bio-material. From figures 09,13 and 17 the results shows the available life for the fatigue analysis for different Bio-materials. From Table-01 for 5000N titanium compound fatigue life is 43985 , for tempered steel 38196 and for cobalt-chromium combinations fatigue life is 36399 and we can also see graphical view. So it is clear that Ti-6AL-4v has more cycle compared to other bio-materials 
DOI: 10.17148/IARJSET.2021.8927

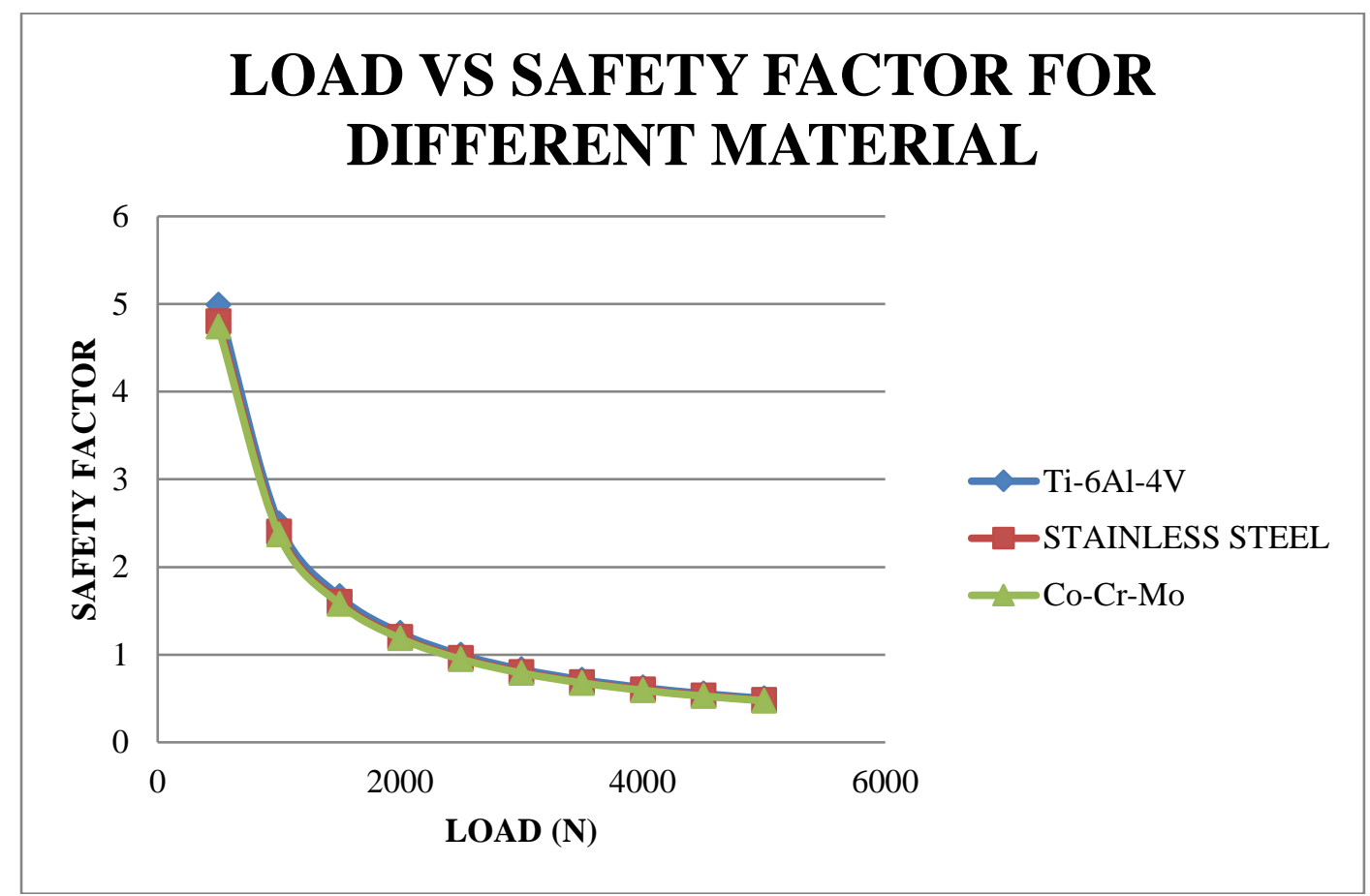

2.Graphical representation of safety for different Bio-materials

Above figure shows the schematic representation of the safety of factor different bio-material. From Table 02 and graphical representation observed that tempered steel and cobalt-chromium composites has great risk compared to titanium combination.

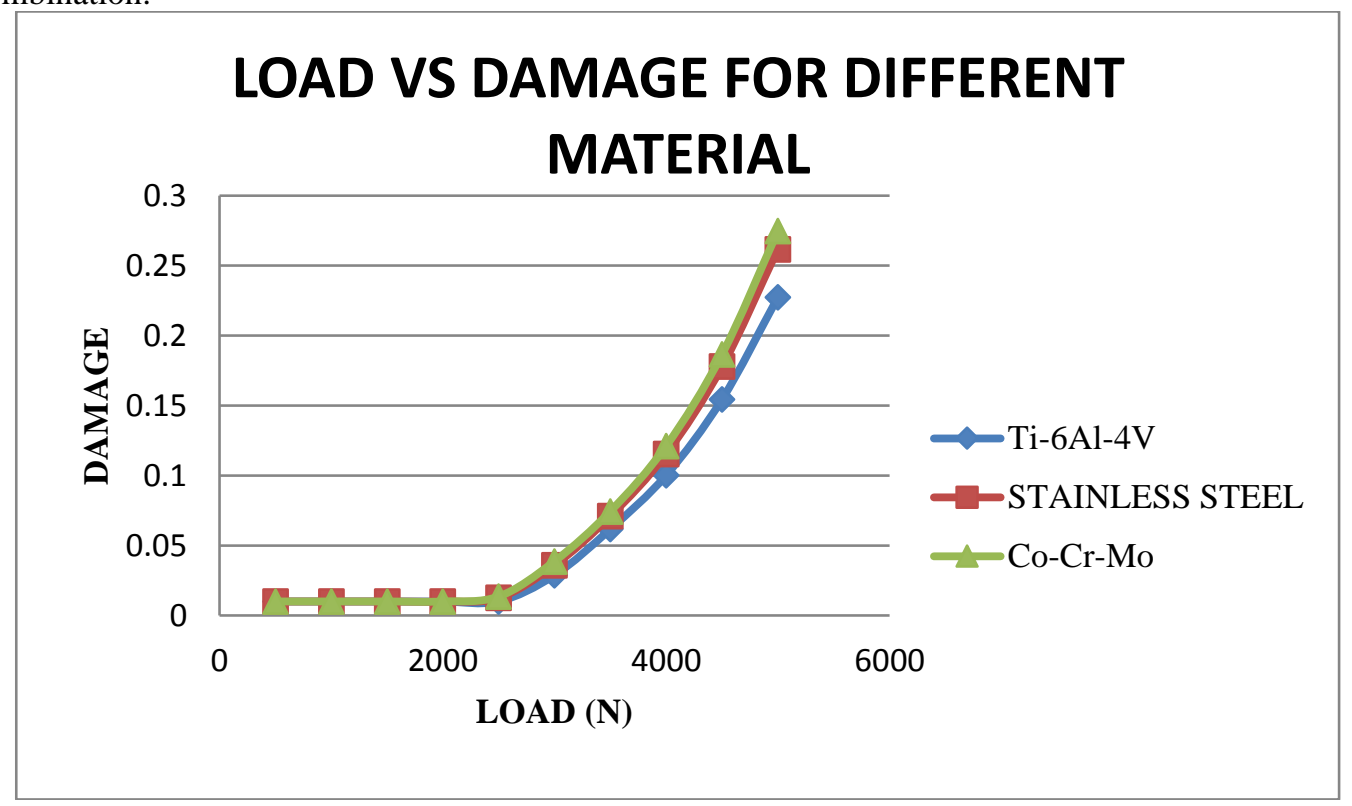

3. Graphical representation of damage for different Bio-materials

Above figure show the schematic representation of the damage for different bio-material. From Table-03 and graphical representation it observed that compared to tempered steel and cobalt-chromium composites the titanium combination has lesser damage. 
DOI: 10.17148/IARJSET.2021.8927

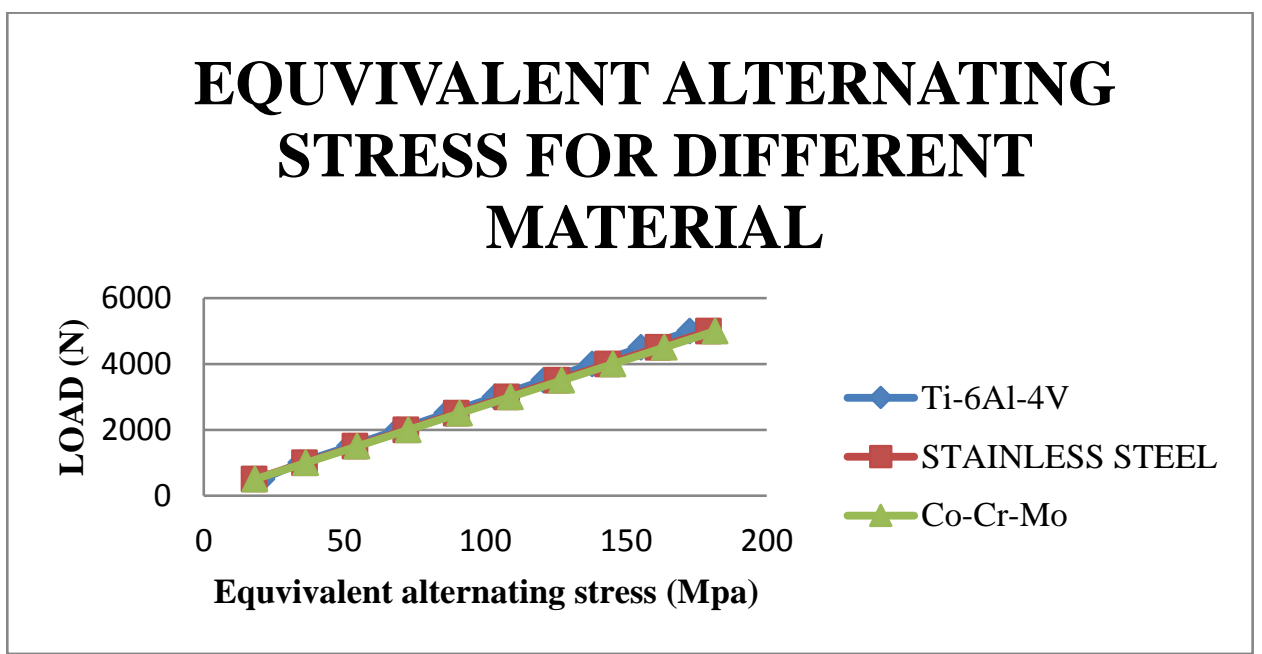

4. Graphical representation of equivalent alternating stress for different bio-materials

Above figure show the schematic representation of the equivalent alternating stress. From Table-04 and graphical representation it observed that for Ti-6Al-4V the peak equivalent alternating stress is $172.63 \mathrm{MPa}$ and for the stainless steel the peak equivalent alternating stress is $179.4 \mathrm{MPa}$ and lastly for the Co-Cr-Mo the peak equivalent alternating stress is 181.77 .

\section{CONCLUSION}

\section{IV.CONCLUSION AND FUTURE WORK}

This examination demonstrated as the proficient procedure for assessment of the prosthesis with various materials under certain stacking condition. This would be an exceptionally precise endeavor in getting exhaustion information the reality can be finished up by this examination as:

Here on the off chance that we made a knee joint model utilizing appropriate programming. Also, it is seen from the above outcomes that Titanium (Ti-6Al-4V) is the best material for the determination of knee embed in light of the fact that it shows the lesser comparable substituting pressure at the high stacking condition than the other material. Also, Ti$6 \mathrm{AL}-4 \mathrm{~V}$ has more cycle contrasted with other bio-materials. Tempered steel and Co-Cr-Mo has more serious danger contrasted with Ti-6Al-4V. Also, something more is that Ti-6Al-4V has lesser harm contrasted with other biomaterials.

\section{Future work}

As we considered Titanium alloy (Ti-6Al-4V), Stainless steel and Co-Cr-Mo for femoral part, the materials can be changed with different bio-materials.

$>\quad$ For our study we only choose ANSYS software for fatigue analysis and the study can be done from n-code software also.

$>\quad$ For this study the experimental tests can also be conducted.

\section{ACKNOWLEDGMENT}

I sincerely thanks to Prof.S.J.Sanjay sir for their guidance and support to do this work. I also thank to Dr. M.S.Hebbal sir for their assistance as Coordinator for the program.

\section{REFERENCES}

1. Yash Shah, Ashish Bhave and Vaibhavi Sonetha - Fatigue Analysis of the Knee Joint International Conference on Advanced Computing Technologies and Applications ICACTA-2015.

2. Suwattanarwong Phanphet Surangsee Dechjarern and Sermkiat Jomjanyong - Above-knee prosthesis design based on fatigue life using finite element method and design of experiment, January 2017.http://dx.doi.org/10.1016/j.medengphy.2017.01.001

3. B.R.Rawal, Amit Yadav and Vinod Pare - Life estimation of knee joint prosthesis by combined effect of fatigue and wear. $3^{\text {rd }}$ International Conference on Innovation in Automation and Mechanical Engineering,ICIAME2016

4. Roger LEMAIRE,- Fatigue fracture of the femoral component in a mobile bearing Knee prosthesis, April 2010,https://www.researchgate.net/publication/44631717

5. Jharana deoriya -"stress analysis of knee joint and knee prosthesis".2014

6. JHNFEN SHI-Finite element analysis of total knee replacement considering gait cycle load and malalignment 2007

7. Uzair N.Mughal, Hassan A.Khawaja and M.Moatamedi -Finite element analysis of human femur bone. Int.Jnl.of Multiphysics Volume 9.number 2.2015

8. S.H.Teoh - Fatigue of biomaterials: a review. International journal of Fatigue 22(2000)825-837

9. https://en.m.wikipedia.org/wiki/Fatigue (material)

10. https://www.sciencedirect.com/topics/engineering/fatigue-failure

11.https://youtu.be/xVOb_CmmddY 